\title{
Scientific and Research Work of the Future Teacher as a Necessary Condition for the Formation of Self- Educational Competence
}

\author{
Natalia Berezenko ${ }^{[0000-0003-3333-8924]}$, Julia Demchenko * [0000-0002-2247-7470] \\ Central Ukrainian State Pedagogical University named after V. Vynnychenko, Kropyvnytskyi, Ukraine \\ *nberezenko29@gmail.com
}

\begin{abstract}
The article describes the research activities of students as a pedagogical condition for the formation of self-educational competence of a future mathematics teacher. The specifics of the formation of the self-educational competence of the future teacher of mathematics in the conditions of the educational process of the higher pedagogical educational institution are reflected. The content, peculiarities, results of experimental work of influence of research work on formation of self-educational competence of the future teacher of mathematics are disclosed. The criteria for the formation of self-educational competence of future mathematics teachers have been identified. It has been experimentally tested and proved that the research work of the future teacher is a prerequisite for the formation of selfeducational competence. The research activities of the future teacher of mathematics should be based on an understanding of its structure, an awareness of a consistent algorithm aimed at solving current issues of the educational process of a general educational institution and should be determined by the model of professional training of the future teacher of mathematics. The organization of research work of students in a higher educational institution should be carried out in two areas: the scientific work of students in the framework of the educational process and the scientific work of students outside the educational process. The results of the study of the impact of research activities on the formation of self-educational competence of a future teacher of mathematics make it possible to draw the following conclusions: the participation of future specialists in research activities is an effective factor in the formation of their self-educational competence; such students have a higher level of self-educational competence; dynamics of selfeducational competence index increase in the experimental group representatives can be traced more intensively than in the control group students.
\end{abstract}

Keywords: self-educational competence, future teacher, research work, formation, professional training, experimental work.

\section{INTRODUCTION}

The new requirements for personality and the modern state of development of society put forward, forms a dynamic and creative person who is active, able to independently make decisions and achieve their goals. The formation and development of each individual is a painstaking and time-consuming process in which the activities of teachers in general education institutions are of paramount importance. The problem of competence of a specialist becomes relevant, the purpose of which is the formation of a comprehensively harmoniously developed person with analytical thinking. Such competence is the result of many factors and the synthesis of concepts, one of which is the selfforming competence of a mathematics teacher who can form the analytical thinking of a student [1]. Mathematical education has always existed at the fuzzy intersection of mathematics and education. In addition, in mathematical education, the poles of reform and traditional learning can separate the community. We are now at a crossroads in terms of priorities related to the future of the planet. [2]

One of the main tasks of pedagogical workers is the constant improvement of professional level, pedagogical skills and general culture. The issue of teacher self-education is quite acute. In addition, the 
teacher's awareness of the importance of forming selfeducational competence and constant desire to acquire new knowledge, formation of skills and abilities of productive creative activity aimed at constant selfimprovement, self-knowledge and self-analysis becomes especially important. One of the important conditions for the formation of self-educational competence of the future teacher of mathematics is research. The teaching profession in its content, functional orientation requires from the individual scientific research, daily creative activity in solving professional problems. Modern school needs a teacher of mathematics - creative, mobile, self-effective. This actualizes the problem of organizing research activities of students of pedagogical universities as a means of forming self-educational competence. The society of the future, for which highly qualified specialists are trained, cannot be satisfied with specialists who are carriers of a certain amount of scientific information [3].

The problem of research work of the teacher is fully covered in science. In addition, the topic has a deep historical background. At the present stage, attention is focused on the theoretical basis of research activities and features of the organization of research work of students. This training largely takes place in higher pedagogical educational institutions by involving students in research work. Such work is designed to ensure the development of future teachers' inclinations to search activities, to creatively solve educational problems at school, as well as the formation of skills and abilities to apply research methods to solve pressing problems of education.

The issue of the peculiarities of the research work of the future mathematics teacher as a necessary condition for the formation of self-educational competence of the specialist and the peculiarities of the organization of the educational process in higher education as a prerequisite for the organization of research work of mathematics teachers at school [4].

\section{RESEARCH METHODOLOGY.}

In our research we describe how the future specialist achieves a certain result, how the appropriate pedagogical influence helps or prevents the future specialist to realize their potential during research as a means of forming self-educational competence of the future teacher of mathematics. As a result, we have identified the following criteria, indicators and levels of formation of self-educational competence: motivational and value (awareness of the professional orientation of the process of self-development, ensuring a positive attitude and interest in self-educational activities); cognitive (knowledge and understanding of the subject area); organizational and activity (skills and abilities from the experience of educational activities, practical and operational application of knowledge).

The proposed quantitative criteria are experimentally established intervals of values of indices - motivational-value, cognitive and organizational-activity. Variants of their intersection are formed by specific levels of formation of selfeducational competence in the process of professional training of future mathematics teachers. Determining the criteria and indicators of the formation of selfeducational competence of future mathematics teachers allowed to distinguish three intervals of numerical values of the index and to fill the levels of formation of self-educational competence of future mathematics teachers. We have identified three main levels of selfeducation competence of future mathematics teachers: high, medium, low. The boundaries of these intervals characterize a certain level of formation of selfeducational competence of the future teacher of mathematics. The level has a quantitative and qualitative explanation. The experimental values of each index vary from 1 to 5 . We considered the formation of self-educational competence as a necessary quality of the future teacher of mathematics and, at the same time, as one of the signs of his readiness for teaching, as a link that ensures a successful transition from higher education to training Each of the criteria we identified, which determined the levels of formation of self-educational competence of future teachers of mathematics, in the real pedagogical reality was through certain semantic indicators. We took into account the research proposed in determining the features of the formation of self-educational competence of the future teacher of mathematics during his training [5]. To determine a certain level of selfeducational competence of students developed a stereo questionnaire, the content of which contains indicators of motivational-value, cognitive, organizationalactivity criteria for representatives of experimental, control groups and for experts.

Based on a survey of experts, which were the heads of faculties, departments, teachers and active groups, the coefficients of the specific weight of each indicator were determined, which determines the importance of forming the self-educational competence of the future mathematics teacher:

1. Knowledge of the basic training course of the specialty, mastery of techniques of mental activity 0.12 .

2. External and internal characteristics of the image of the specialist (speech, facial expressions, pantomime, voice, business attire) - 0.08 .

3. Participation in scientific circles, sections, Olympiads, seminars, conferences - 0.09. 
4. Planning of own activity and organization of activity of pupils - 0,07.

5. Pedagogical technologies, forms, methods, means, methods of teaching - 0.14 .

6. Constant updating of knowledge, processing of the received information $-0,19$.

7. Vision of the beautiful in art, perception of the beautiful, ugly, good, evil, etc. - 0.05 .

8. Self-awareness, discovery of humanism, recognition of man as the highest value -0.09 .

9. Participation in physical culture and health activities, healthy lifestyle -0.06 .

10. Participation in the life of the team, group, faculty, university, participation in solving social problems - 0.11 .

The total sum of the coefficients of the indicators of all ten components is equal to one. The results are evaluated on a scale: 5 - excellent result; 4 - good result; 3 - satisfactory result; 2 - the result is insignificant; 1 did not participate, did not perform; 0 - there was no such activity.

According to this scale of measurement and normalized coefficients of specific weight of indicators, the value of the index of criteria of self-educational competence of a student and his academic group will be in the range from 1 to 5. , substantiated by O. P. Kuprian [6].

The general index of formation of self-educational competence of respondents of the experimental group is built on the basis of correlation of values of three indices - motivational-value criterion (IMV), cognitive (IC) and organizational-activity (IOA). To combine them, a technique is used - the calculation of the average cubic value of the data of the three source indices.

$$
I S C=\sqrt[3]{I_{m v c} \cdot I_{c} \cdot I_{o a}}
$$

where: Imvc - index of motivational-value criterion,

Ic - index of cognitive criterion,

Ioa - index of organizational-activity criterion.

The next stage - the establishment of changes that should occur in the self-education of students after the implementation of these conditions on the basis of the appropriate pedagogical influence on the motivationalvalue, cognitive, organizational-activity criteria. Carrying out of the specified research is based on comparison of results of representatives of experimental and control groups: experimental group $\mathrm{x} 2 \mathrm{e}-\mathrm{x} 1 \mathrm{e}=\mathrm{A}$; control group $\mathrm{x} 2 \mathrm{k}-\mathrm{x} 1 \mathrm{k}=\mathrm{B}$, where $\mathrm{x} 1 \mathrm{e}$ is the state of the system of the studied object to the action of the pedagogical stimulus in the experimental group; $\mathrm{x} 2 \mathrm{e}$ - the state of the same system after the stimulus. Symbols $\mathrm{x} 2 \mathrm{k}$ and $\mathrm{x} 1 \mathrm{k}$ - indicate the initial and final state of a similar system in the control group, respectively. The criterion for confirming or refuting the hypothesis is the presence or absence of a difference between the results of the experimental and control group. In addition, the hypothesis in the experimental study can be considered confirmed if in hypotheses of a positive nature - $\mathrm{A}>\mathrm{B}$ and in hypotheses of a negative nature $-\mathrm{A}<\mathrm{B}$; if $\mathrm{A}=\mathrm{B}$, then we have a formal sign of falsification of the hypothesis in the experiment.

\section{RESEARCH RESULTS}

The main ways of research work of students of higher educational institutions include 1) research work, which is a component of the educational process and mandatory for all students (writing essays, practical and control work, preparation and defense of term papers and dissertations, master's theses, performance of research tasks during production practice at the request of enterprises, etc.); 2) research work of students outside the educational process, ie participation in scientific circles, the implementation of self-supporting scientific work within the creative cooperation of the departments of the faculties. The content and structure of educational and research work of students are determined by the continuity of its means and forms in accordance with the logic and sequence of the educational process, which causes a gradual increase in the volume and complexity of acquired knowledge, skills and abilities. The complexity of the content and methods of research work of students depends on the stage of study [7]. The research activity of a mathematics teacher should be an integral characteristic of the educational process in a higher educational institution. However, there are questions of students' motivation to implement search activities, the availability of the necessary knowledge for the implementation of the research process (experimental methods), knowledge of the cycle of mathematical disciplines, as well as the actual practice of organizing and conducting experiments and search activities [8]. The process of organizing research activities of students - future teachers of mathematics becomes important. For a more detailed description of this aspect and to determine the level of self-education competence of future mathematics teachers, we recorded the data using numerical indices, which allowed a comparative analysis of their changes.

Our research has shown that the index of selfeducational competence of students who are involved in the conditions of research activities is much higher and changes more intensively compared to students who do not participate in research activities. The obtained data, presented in Table 1, show that the index of self-education competence of future mathematics teachers who participate in research activities is 
determined by the interval - 3.01-3.5, and those students who are not engaged in research - 2, 01-2.5. That is, there is a statistically significant difference in the level of identification of self-educational competence of students - future teachers of mathematics of the two samples.

The active participation of the future specialist in mathematics in research is closely correlated with the growth of his self-educational competence. Thus, the involvement of students in the organization of research activities is an effective pedagogical condition for the formation of his self-educational competence in the field of mathematics. The generalized data of table 1 show the difference between the interval values of the indices of self-education competence of future mathematics teachers who take an active part in the organization and conduct of research activities and those students who stay away.

Table 1. Generalized value of indices of self-educational competence of students who are active participants in research activities and those who do not participate in it (in abs. Vel.),

\begin{tabular}{|c|c|}
\hline $\begin{array}{l}\text { Students participating in research activities } \\
(\mathrm{H}=46 \text { people })\end{array}$ & $\begin{array}{l}\text { Students who do not participate in research activities } \\
(\mathrm{H}=46 \text { people })\end{array}$ \\
\hline 3,33 & 2,31 \\
\hline
\end{tabular}

In the process of research and experimental work, we found that the direct participation of future teachers of mathematics in research is closely linked with the willingness to professional self-improvement, understanding the need for research in the educational process and awareness that during work can not be avoided errors. In addition, the implementation of research activities is better for those students who have their own vision of a particular problem, show focus and focus on achieving the goal. It is those students who have formed an understanding of all these aspects, and take an active part in research activities, and, accordingly, demonstrate a higher level of selfeducational competence, compared to their colleagues, who do not have these characteristics.
A comparison of the value of the index of selfeducational competence of representatives of control and experimental groups of future mathematics teachers shows that those students who are involved in the organization of research activities have a much higher indicator of self-educational competence. The value of the index of self-educational competence of future mathematics teachers who carry out search activities falls in the numerical range - 3.01-3.5, in students who do not carry out research activities - in the range of 2.01-2.5. These results indicate a significant and statistically significant difference in the degree of self-education competence of future mathematics teachers in relation to these sample populations. To illustrate the statistics, we offer Figure1.

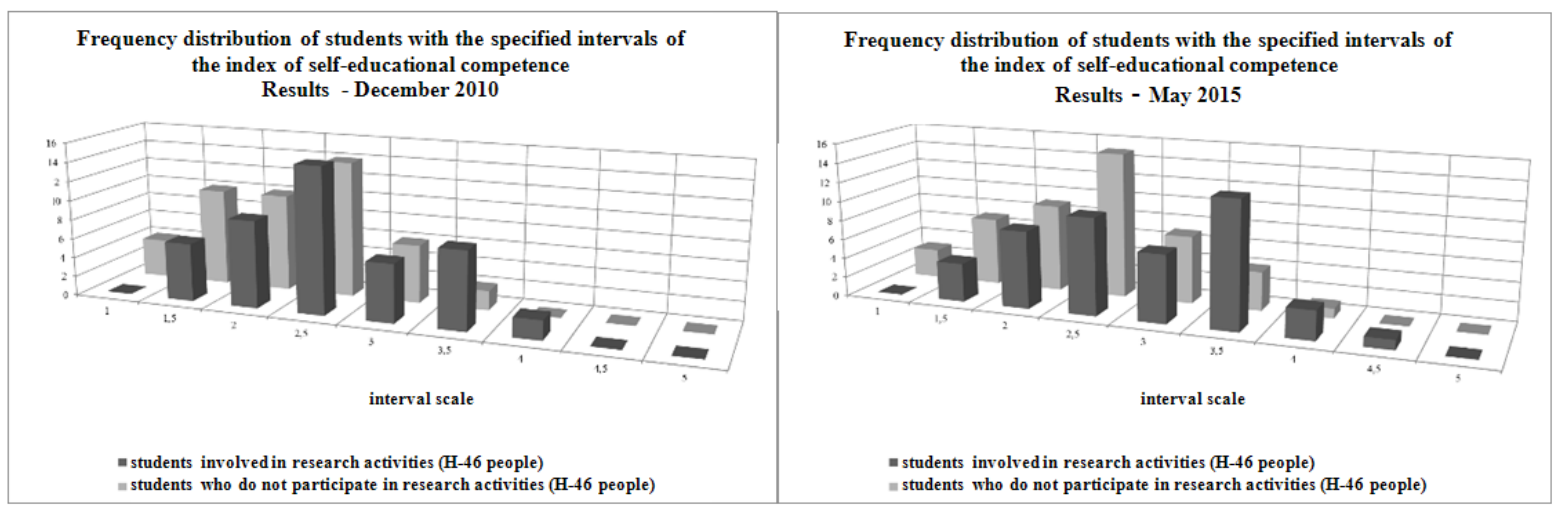

Figure 1 Frequency distribution of students with the specified intervals of the index of self-educational competence

There fore, according to figure 1 . The results of the second diagnostic section of the students involved in the experiment, which was conducted after the implementation of the selected condition, are as follows. The highest value of the level of self- educational competence was given to those students who were involved in the organization and conduct of research activities (compared to the data of the zero diagnostic section). The second diagnostic section shows that the index of self-educational competence of 
a group of students engaged in research activities increases compared to students who are not involved in the organization of search activities.

Focusing on the selected criteria and indicators of self-educational competence of students - future professionals, we analyze in detail the data obtained and determine the general level of formation of selfeducational competence of the future teacher of mathematics. The quality of organization, conduct and activity of students in research activities depends on the motivation of the future specialist. As the analysis of the real practice of training future mathematics teachers showed, the leading motives that reflect the student's focus on research activities are curiosity and interest in solving pedagogical problems.

The formation of curiosity as a necessary component of the motivational and value criterion of self-educational competence of the future teacher of mathematics is conditioned by the constant desire to expand and deepen knowledge, to obtain new facts. A necessary prerequisite for curiosity is the reaction of the individual to the novelty, uncertainty of the object, the desire to determine its essence. Due to the fact that curiosity is associated with the volitional efforts of the student, it becomes an important stimulus for the education of purposefulness, perseverance, the desire to complete the activity. Steady curiosity can serve as a sign of formation in students - future researchers of motivation to formation of self-educational competence.

The next leading motive that directs the student to research activities is the interest in solving the pedagogical problem. Interest is defined as an emotionally conscious, selective orientation of the individual, addressed to the subject and activities associated with it, accompanied by inner satisfaction with the results of this activity. This interest has a search character, which increases the possibilities of mental development of the student, promotes conscious independence, causes productive work, changes the ways of mental activity, is a condition for the development of creative personality. Since the basis of interest in solving pedagogical problems are thought processes, it can be considered one of the motives for the implementation of research activities of the future teacher of mathematics. The formation of motivation in the field of self-realization as a future researcher is determined by the desire to participate in the main forms of research activities within the curriculum of the university and beyond.

Focusing on the fact that the initial link in the implementation of the student in the role of researcher is the writing of scientific papers, we understand the importance of this type of activity. The figure of a supervisor is important, which should motivate the student and show him the difficult world of organizing and conducting research. The teacher of a higher educational institution faces a difficult task - not only to transfer basic knowledge, skills and abilities, but to form a constant thirst of the student for research activities.

A necessary aspect of the formation of motivational and value criteria of self-educational competence of the future teacher of mathematics is the development of his sense of so-called healthy doubt, which encourages to test their assumptions and assumptions, reject the wrong and work out the right. The teacher of the higher educational institution should organize the educational process so that for students mathematics becomes a process and a result of continuous creative search. During the involvement of students in research activities, we focused on stimulating his professional self-education, developing initiative, forming a personal style of educational activities, taking into account personality traits and level of training. This helps to increase the interest of the student - the future specialist in the chosen profession by reducing the intensity of the difficulties he faces, providing additional prospects for the realization of abilities, consolidation in the future work team [9].

Based on the analysis of real practice, the motivational and value criterion of self-educational competence of the future teacher of mathematics can be analyzed from the standpoint of the organization of research activities during the educational process and beyond. Motivational and value criterion for the organization of research activities is determined by the following features: the desire to independently deepen knowledge, exploration and improvement of professional training in mathematics; managing one's own research work on the basis of conscious motives and goals of activity; interest in the constant updating of knowledge, skills and abilities through exploratory pedagogical activities aimed at the application of selfeducational competence in the activities of a mathematics teacher; the need for systematic research activities; the desire to make self-analysis and selfassessment of professional and research activities; systematic desire for self-improvement, finding ways of self-affirmation in the teaching profession; improving their individuality, the desire for creative self-realization in the process of research professional activity [10].

Analysis of the organization of the educational process in higher education and the results of cooperation with experts who participated in our study, show that most graduates of higher educational institutions have almost no curiosity and interest in solving scientific problems. This is evidenced by the results of the zero diagnostic section. At the same time, participation in research activities is more active if students have a motivational orientation. Comparing 
the numerical intervals, it can be stated that the representatives of the experimental group at the beginning of the experiment have a numerical interval of $2.51-3.0$, after the introduction of the condition 3.01 - 3.5. For students of the control group - almost the same in the numerical range from 2.01 to 2.5 . A detailed presentation of the results of diagnostic sections to identify motivation for the development of self-education competence of future teachers of mathematics is given in Figure 2.
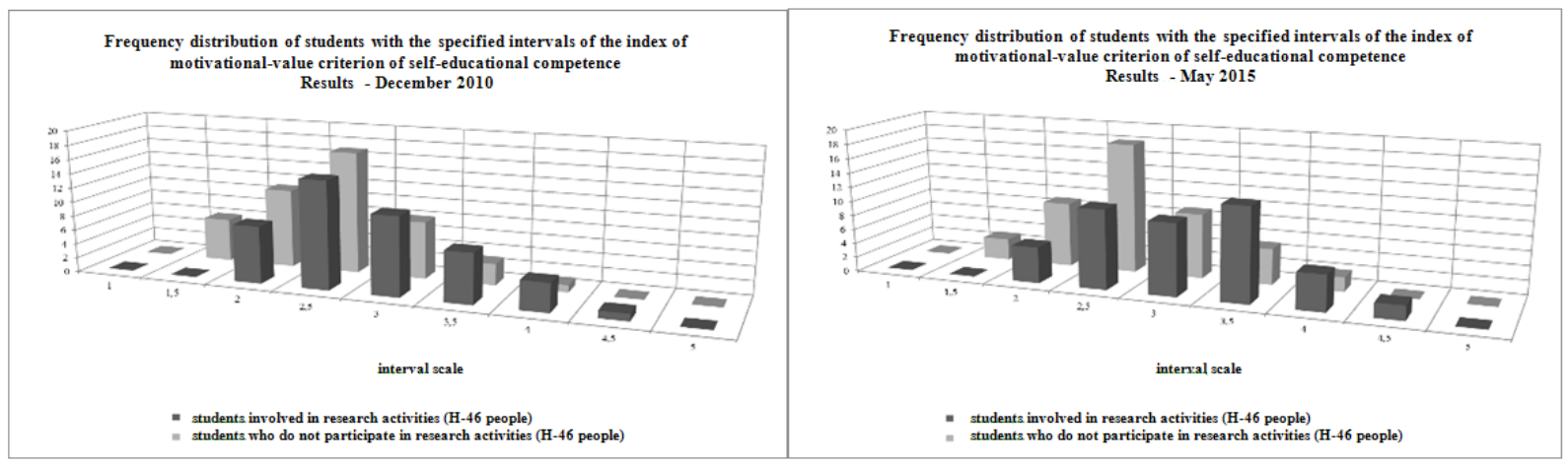

Figure 2 Frequency distribution of students with the specified intervals of the index of motivational and value criterion (IMV) of self-educational competence

A ranking analysis of the content of indicators of self-educational competence of future mathematics teachers is presented, which helps to explain more meaningfully the reasons and circumstances that affect the process of effective formation of self-educational competence in a higher education institution. Ranking indicators are shown in Table 2.

According to Table 2, it is seen that the ranks of students who show and do not show motivation to organize and conduct research activities have significant differences.

Thus, the representatives of the experimental group in the first place was the indicator of planning their own activities and the organization of students. Students understand that planning their own professional activities contributes to the orderliness and harmony of the work of a modern mathematics teacher. Having a plan with priorities and the right approach to the tasks help the future specialist to organize daily affairs, not to lose the main thing, to have time to do exactly what will contribute to the desired result, and at the same time not to feel good. The ability to rationally allocate working time and leisure time plays a crucial role in professional activities. In addition, attention should be paid to the technology of achieving effective results and factors that affect the efficiency of work. In particular, these are: the correct distribution of workload; hard work of the individual and biorhythms (influence of biorhythms on the distribution of working time); rules for organizing effective recreation; effective sleep; ability to tune in to solve problems; self-motivation as an effective solution of time-consuming tasks, small unpleasant tasks, etc. Students who are motivated to research, note that the ability to effectively allocate time is an integral part of self-educational competence of the teacher.
The second rank of motivational and value criterion of self-educational competence, respondents determine the value of participation in scientific circles, sections, competitions, seminars, conferences. The level of students' motivation is also determined by the teacher's personal interest in professional growth; a system of beliefs and value orientations regarding the essence and purpose of the process of forming the skills necessary for the successful implementation of research activities; the desire for self-improvement through an understanding of the value role of this process in improving the training of future professionals. In the last place among students who were motivated to participate in research activities, there is an indicator that reflects the vision of the beautiful in art, the perception of beautiful, ugly, good, evil and more.

Students do not pay due attention to the formation of aesthetic tastes and ideals as a necessary condition for the development of motivation for research. The originality of the rankings of the indicators of motivational and value criterion of self-educational competence, presented in Table 2 . is reflected by a group of respondents who were not involved in research activities. The first rank of the motivationalvalue criterion of self-educational competence has the indicator of constant updating of knowledge and processing of the received information. The last rank, which is determined by knowledge of the basic training course of the specialty, mastery of techniques of mental activity, according to students, is not a defining characteristic in the process of forming motivation for research. The implementation of research and experimental research on the implementation of the condition for the formation of motivation to carry out research activities suggests that those students who have a desire to search for activities are different from other colleagues. This difference is characterized by the 
formation of a lasting interest in research and the desire for self-educational competence through constant selfimprovement and the discovery of new scientific facts.
They, compared to other students, are more easily involved in the organization and conduct of search activities [11].

Table 2. Rank analysis of the content of indicators of motivational and value criterion of selfeducational competence of students who take and do not participate in research activities

\begin{tabular}{|c|c|c|}
\hline \multirow[b]{2}{*}{ Indicator of motivational and value criterion } & \multicolumn{2}{|c|}{ Groups of respondents } \\
\hline & $\begin{array}{l}\text { Students participating in } \\
\text { research activities }(\mathrm{H}=46 \\
\text { people) }\end{array}$ & $\begin{array}{l}\text { Students who do not participate in } \\
\text { research activities ( } \mathrm{H}=46 \text { people) }\end{array}$ \\
\hline 1 & 2 & 3 \\
\hline $\begin{array}{l}\text { Knowledge of the basic training course of the } \\
\text { specialty, mastery of techniques of mental } \\
\text { activity }\end{array}$ & 8 & 10 \\
\hline $\begin{array}{l}\text { External and internal characteristics of the } \\
\text { image of the specialist (speech, facial } \\
\text { expressions, pantomime, voice, business } \\
\text { attire, etc.) }\end{array}$ & 6 & 3 \\
\hline $\begin{array}{l}\text { Participation in scientific circles, sections, } \\
\text { competitions, seminars, conferences }\end{array}$ & 2 & 4 \\
\hline $\begin{array}{l}\text { Planning of own activity and the organization } \\
\text { of activity of pupils }\end{array}$ & 1 & 2 \\
\hline $\begin{array}{l}\text { Pedagogical technologies, forms, methods, } \\
\text { means, teaching methods }\end{array}$ & 3 & 5 \\
\hline $\begin{array}{l}\text { Constant updating of knowledge, } \\
\text { processing of the received information }\end{array}$ & 4 & 1 \\
\hline $\begin{array}{l}\text { Vision of the beautiful in art, perception of the } \\
\text { beautiful, ugly, good, evil, etc. }\end{array}$ & 10 & 9 \\
\hline $\begin{array}{l}\text { Self-awareness, the discovery of } \\
\text { humanism, the recognition of man as the } \\
\text { highest value }\end{array}$ & 5 & 6 \\
\hline $\begin{array}{l}\text { Participation in physical culture and } \\
\text { health activities, healthy lifestyle }\end{array}$ & 7 & 7 \\
\hline $\begin{array}{l}\text { Participation in the life of the team, group, } \\
\text { faculty, university, participation in solving } \\
\text { social problems }\end{array}$ & 9 & 8 \\
\hline
\end{tabular}

\section{CONCLUSIONS}

The results of research work confirm that the effective formation of self-educational competence of the future teacher of mathematics requires his involvement in research activities, which contributes to the development of motivation, the desire to acquire new knowledge and implement specific actions in this direction. The most effective activities to develop the self-educational competence of future mathematics teachers when involving them in research activities are: planning their own activities and organizing the activities of students; participation in scientific circles, sections, olympiads, seminars, conferences; participation in the life of the collective, group, faculty, university, participation in solving social problems, which are decisive aspects in the way of developing the self-educational competence of future specialists.

The results of the study of the impact of research activities on the formation of self-educational competence of a future teacher of mathematics make it 
possible to draw the following conclusions: the participation of future specialists in research activities is an effective factor in the formation of their selfeducational competence; such students have a higher level of self-educational competence; dynamics of selfeducational competence index increase in the experimental group representatives can be traced more intensively than in the control group students. The study does not cover all aspects of the problem. In the future it is planned to study the scientific prerequisites for the readiness of primary school teachers to implement research activities.

\section{REFERENCES}

[1] Maryam Abdullah Alzaid, Tahani Soud Alharbi and Moody Abdulrahman (2020), "Data Mining Methods for Detecting the Most Significant Factors Affecting Students' Performance", I.J. Information Technology and Computer Science, vol. 5, pp. 1-13, available at: http://www.mecspress.org. DOI: 10.5815/ijitcs.2020.05.01

[2] Kajander, Ann (2021), "The Mandate of Scholarly Mathematics Education Research: Moving Ourselves Forward". Canadian Journal of Science, Mathematics and Technology Education. DOI: 10.1007/s42330-020-00121-7.

[3] Doug Salt and Junkang Feng (2012), “Using Logic Programming to Represent Information Content Inclusion Relations", I.J. Information Technology and Computer Science, vol. 1, pp. 5063, available at: http://www.mecs-press.org. DOI: $10.5815 /$ ijitcs.2012.01.07

[4] Marín-Cano, Martha \& Parra-Bernal, Lina \& Burgos-Laitón, Sandra \& Grialdo, Mónica \& Scholar, Google (2021), "La práctica reflexive del professor y la relación con el desarrolo professional en el context de la educación superior". DOI: $15 . \quad 154-175$. 10.17151/rlee.2019.15.1.9.

[5] Yixun, Shi (2011), "Problem Solving, Computer Technology, and Students' Motivation in Learning Mathematics", I.J. Education and Management Engineering, vol. 1, pp. 1-5, available at: http://www.mecs-press.net. DOI: 10.5815/ijeme.2011.01.01

[6] Kupriyan, A.P. (1976), Methodological problems of social experiment, Moscow, $156 \mathrm{p}$.

[7] Shkvyr, O. (2016), "Research Work as a Means of the Future Primary School Teachers Training to Research Activity", Pedagogical Discourse, Issue 20, pp. 197-201.

[8] Xiaodong Wanga and Yingjie Wub (2012), "Exploration and Practice for Evaluation of Teaching Methods", I.J. Education and Management Engineering, vol. 3, pp. 39-45, available at: http://www.mecs-press.net. DOI: 10.5815/ijeme.2012.03.06

[9] Liu, Yanan \& He, Wanli \& Guo, Shiri \& Zhou, Wenhui \& Yu, Dengguang (2021), "A WholeProcess Innovative Education on Undergraduate Students Based on Scientific Investigations". DOI: 10.2991/assehr.k.210121.057.

[10] Villarreal, Jorge \& Sastoque, Jairo \& Hincapié Montoya, Mauricio \& Henao Villa, Cesar. (2021), Caracterización de la competencia digital de docentes de Educación Superior, Percepción sobre el uso y alfabetización tecnológica.

[11] Sánchez, Manuel and Alís, Jaime (2021), Evaluación y competencia científica. DOI: 10.13140/RG.2.2.24300.08324. 